\title{
Sand Drift and Measures to Mitigate Its Impact on the Railway Track
}

\author{
Makhamad MirakhmedovichMirakhmedov ${ }^{a}$, AzamatKhudoyorov $^{b}$ \\ ${ }^{\mathrm{a}, \mathrm{b}}$ Tashkent State Transport University,Tashkent, Uzbekistan
}

Article History: Received: 10 November 2020; Revised 12 January 2021 Accepted: 27 January 2021; Published online: 5 April 2021

\begin{abstract}
This research provides an analytical review of measures to mitigate the impact of winds and flow on a railway track based on publications in English, Russian, French, Chinese and Spanish, identifies general and specific experience in the application of measures in a socio-geographical context, consistently sets out their physical and technical characteristics and advantages and disadvantages of technological solutions, identified prospects for further research to improve their technical, technological and economic efficiency.
\end{abstract}

Keywords: sandy desert, wind, railroad, sand drift, sand mitigation measures, benchmarking

\section{Introduction}

Sand drift is a key issue in the design of railways in arid sandy deserts.

Given the growing volume of new construction of railways, train speeds, we can confidently state the relevance of measures necessary to take to ensure the safety of construction, organize train traffic and maintain maintenance and operation at the level of regulatory requirements.

\section{Measures to mitigate the impact of sand on the railway track}

\subsection{General provisions}

To reduce the negative impact of sand on the railway, the factors leading to sand drift have been identified. The main factor is the wind, specifically its transporting ability - "wind-sand flow" [1]. The list of measures to reduce the (negative) impact of SMM sand in the SMaRT project and the historically formed phrase "sand drift control" carry a similar meaning: we are talking about reducing the negative effects of sand drifts, in this case, on iron the road. It should be recognized that the concept of "mitigation measure" more accurately defines the objective of maintaining the quality of an object that should be protected. Almost all researchers involved in the design of measures to reduce the negative consequences of a plain exogenous process - sand drift $[2,3,4,5,6]$, agree on the methods and methods, moreover, they develop classifications in which measures are reflected consistently on many grounds : causes and process of deflation (sand transfer), consequences (SLS) and solutions (Sand Mitigation Measure - SMM), i.e. mitigation measures for the impact of sand on the site, equivalent to the definition - Mitigation of the negative impact (on the railroad) of sand (plain exogenous process) - WISP [7] or the so-called sand fixing works (SMM) - a term used in an earlier period. As for the term "sanding works", it does not clearly enough reflect the purpose of the work performed, but by default (in context) it means all measures taken (SMM). The term "mitigation" is equivalent to the concept of "reduction", the first is preferable for the unification of terminology, since The United Nations Convention unambiguously defines "to combat desertification, land degradation and mitigate the effects of drought".

From the analyzed literature, it follows that mitigation measures, despite certain preferences of different countries, in their meaning, in general, coincide and are subdivided according to their belonging to animate and inanimate nature into: biological and technical measures.

\subsection{Biological protection measures}

Biological measures aimed at creating sand-loving (psammophytic) plants on moving sand are recognized as the most durable and environmentally friendly.

However, this cardinal and environmentally friendly measure, due to various reasons affecting the possibility of their implementation and effectiveness, is not always possible to implement at least one vegetation period. Therefore, a number of researchers recognize the need to use engineering (technical) measures, but as auxiliary ones to increase the effectiveness of Agroforestry measures, for example, using the physicochemical method: 
layer method, create favorable conditions for germinating seeds or protecting seedlings and cuttings from blowing by the wind and undercutting. windsand flow.

Among scientists and practitioners of the CIS countries dealing with the problem of combating sand drifts, a number of works are known in which the use of technical measures is not supported without urgent need [17, 18, $19,6]$. Even during the construction of the Trans-Caspian Railway V.A. Obruchev rejected the installation of shields [17], proving that they promote the formation of dunes along the railroad bed, from which the wind then carries sand to the unprotected track (this point of view is still dominant, moreover, it is enshrined in the norms for the design of railways in conditions of sandy deserts, as well as in the norms for the protection of the railway from unfavorable phenomena.Instead, V.A.Obruchev proposed to consolidate the sandy areas adjacent to the roadbed by systematic planting of trees and shrubs of mainly local species and sowing grasses.

V.A.Paletskiy in 1888 founded the first sandy forest nursery at the Farab station (Uzbekistan) [18], the area of which has now reached 100 hectares.

Khodzhaev, 1947 [6], Polyakov et al., 1966 [19] and others proposed to combine the biological method with technical measures, the success of which was proved by the device of the green belt in the north of the Sahara and the south of the Kyzylkum desert, on both sides of the highway through the Takla-Makan desert (fig.1a)

a)

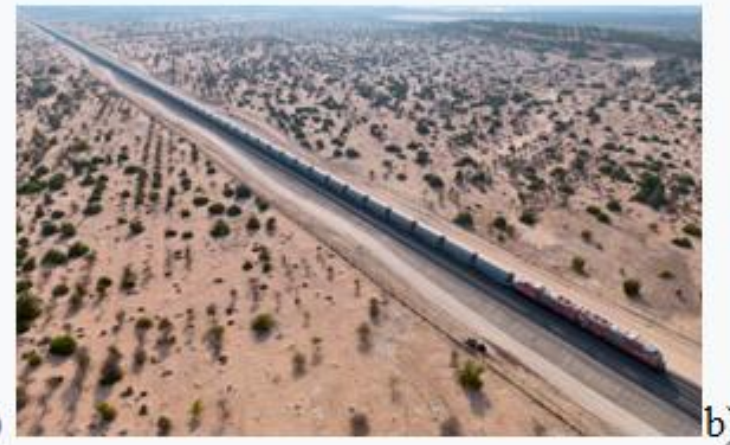

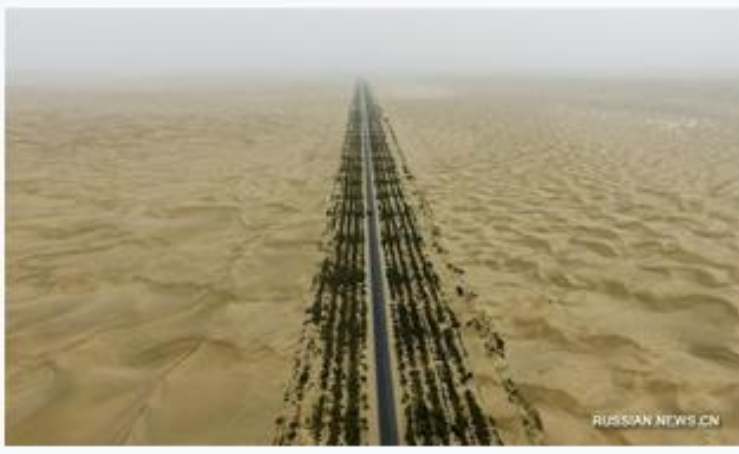

Fig. 1. Agroforestry of sands: Lanzhou-Xinjiang (a), Taklimakan, China (b),

\section{Fundamentals of constructing classifications of measures to mitigate the impact of wind and sand flow on infrastructure in sandy deserts}

\subsection{Technical protection}

In [5], the classification of measures is based on the criterion of non-traceability of a path. Variants of sand fixing technologies are divided by them into phytomeliorative, i.e. aimed at overgrowing sands; technical (fixing with chemical ameliorants and mechanical protection, changing the design of the track superstructure, etc.) and organizational and economic (limiting livestock grazing, fencing areas, etc.). Such a meaningful classification is general and does not reveal the interaction and mutual influence of various options for technologies and methods, does not specify the scope of each of them, does not differentiate the degree of drifts.

In [23], the analysis of empirically tested technological solutions is an attempt to classify measures to protect against drifts and deflation, depending on the purpose, method and means used, into: preventive, phytomeliorative, engineering and complex. Classifications of measures to mitigate the impact of sand on the railroad are found in $[9,10,8,11,12,13,14,15]$. They are compiled depending on the objectives pursued. Historically, the first attempt at categorizing SMM was undertaken by Rahim (1945), who proposed to distinguish "the methods used from time to time to combat evil (sand drift - author)", dividing them into measures taken at the state and local levels [16]. In particular, he proposed a "sand-transfer barrier" for the accumulation-free transfer of sand over the road (Fig. 2a), then modified by other scientists (Fig. 2 b, c). 


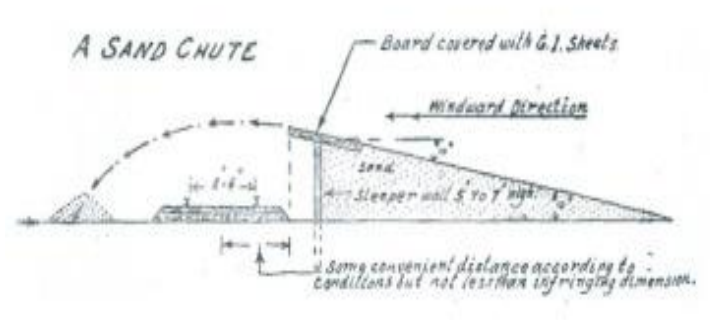

a)

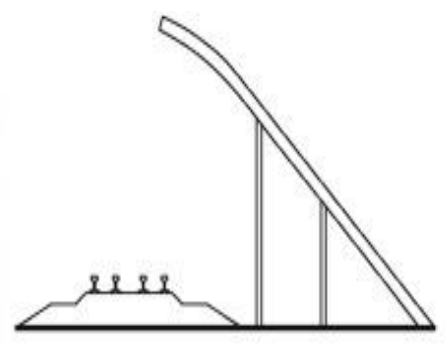

b)

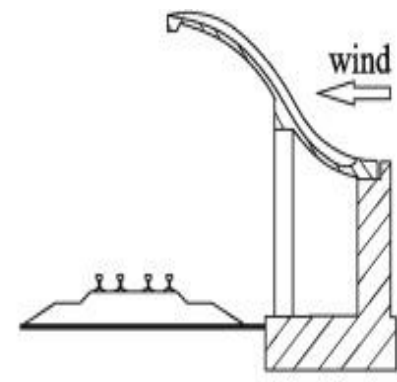

c)

Figure: 2. Construction of sand-transfer barriers: Rakhim, 1945 (a); Guangyong and Peng, 2012 (b); Sato and Ono, 1990 (c).

In foreign practice [8], they are usually called Aerodynamic-based Receivers, which remained at the level of scientific assumptions and are not used in practice.

The so-called mechanical fixing of technical measures is used to block the source of deflation or to intercept the deposition of sand from the stream, which achieves a quick result in fixing sands sand fixing and ending drifts sand; cessation of sand drift. The mechanical method is implemented by installation surface-like: solide barriers; fences and porous fences (Figure 5b), device volume-like: ditshs (Figure 5c), dykes (Figure 5d) and ridge and ditchs (Figure 5e), as well as the so-called checkerboard device.
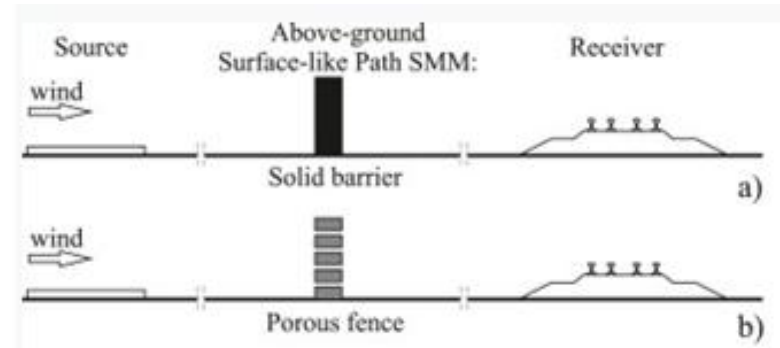

b)
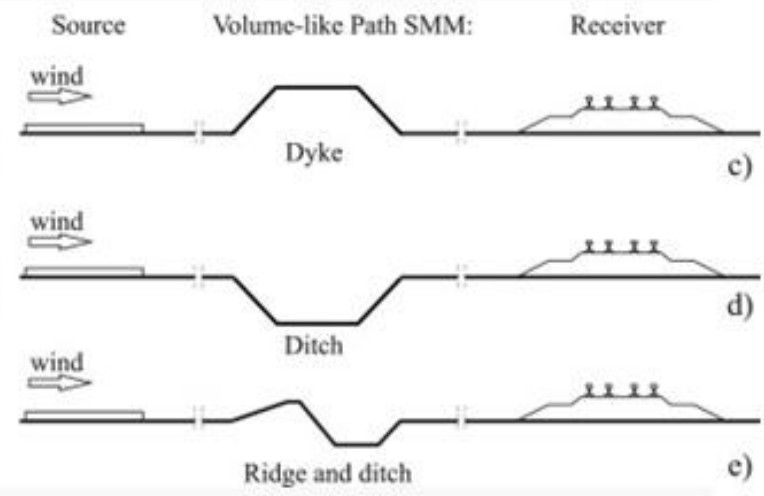

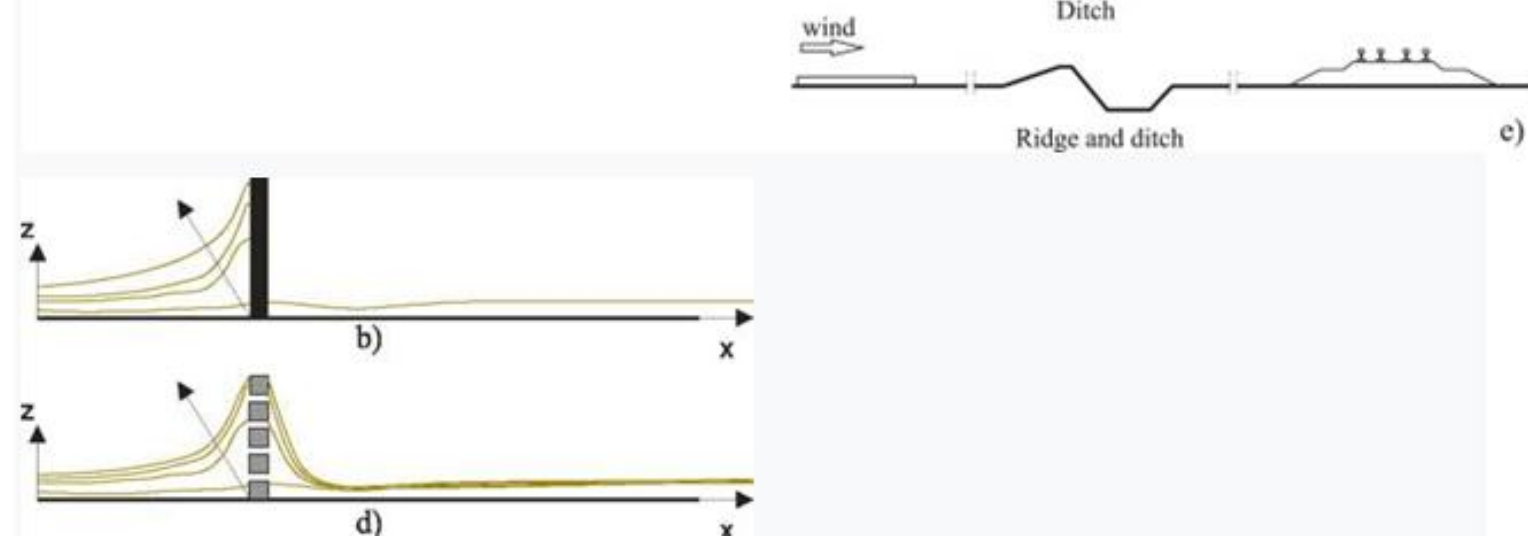

Figure: 3 and 4. Barriers in the form of flat fences: solid (a) and permeable (b); shafts (c), ditches (d) and ditches (e) (Bruno et al., 2018)

Unfortunately, in the twentieth century, the substantiation of the optimal parameters of shield for sand and permeable shields from boards was limited to the results of monitoring the established barriers. The accumulated data and advances in the application of modeling allowed recently to revise the ideas in this area and put forward the idea of replacing vertical fences (Fig. 3 b, d) with curved (Fig. 3 c) [8] so that, to increase the sand-collecting capacity fences and shields on the basis of modeling and experimental aerodynamic testing, the upper part of the vertical barriers should be curved in the upwind direction and form a deflector [2, 8].

At the same time, the idea of using fences and blown snow shields as effective protection measures does not stand up to criticism from the point of view of common sense, because they are technically resource-intensive, technologically labor-intensive and economically unfeasible, except for the case of their use in combination with other measures in the context of creating a forest belt.

In the developed [22], then improved classification [7], all analyzed measures are generalized and reflected in a comprehensive manner. 


\subsection{Volumetric protection}

Revealed regional preference for the use of SMM by types: widespread use of fences and shields in the region of the Arabian Peninsula; cells in China, Central Asia and Brazil; attempts to use "volumetric" [8] barriers: ditches, shafts and ditches in Central Asia [3, 22, 24] and the Arabian Peninsula [8]. Obstacles are called volumetric, apparently because they have three significant dimensions: length, height and width, as opposed to fences and shields that have only two dimensions: length, height.

The volume barriers also include low barriers made of reeds, straw, palm branches, etc. materials of plant origin, as well as artificial woven and non-woven materials in the form of cells are called checkerboard device, because have three dimensions: the size of the cage in the plan (length, width) and height.

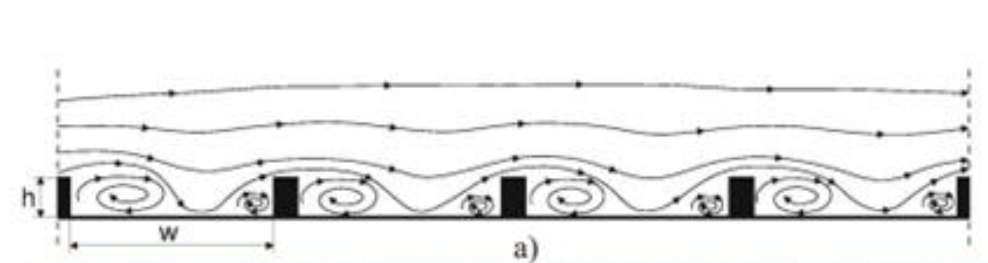
a)

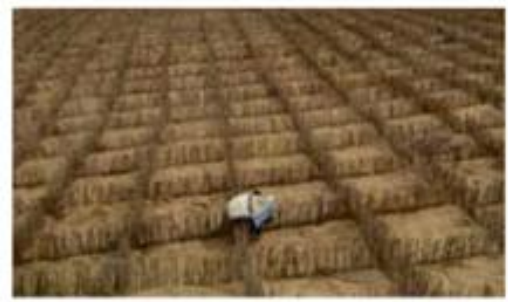

c)

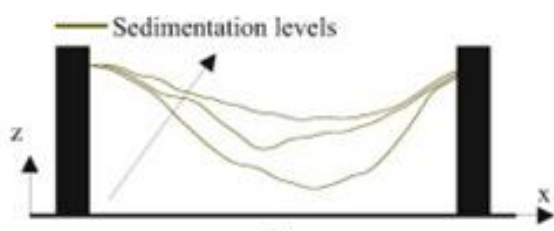

b)

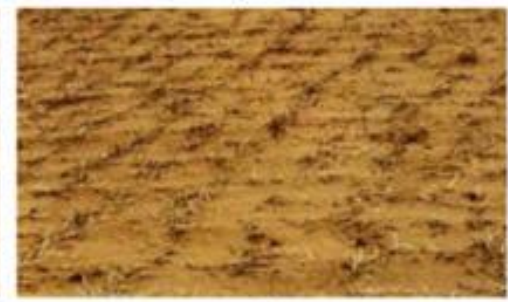

e)

Figure6. Cell protection from reeds: schemes: placement of standing rows of reeds (a) and sand deposits (b); cell states: initial (c), in the process of filling with sand (d) and filled with sand (e)

\subsection{Physicochemical measures}

Since the 40s of the XX century, a number of scientists have widely experimented with various binders, developing the theoretical and practical foundations of the physicochemical method (PCM) for fixing mobile sands. FHM is devoted to the works of a number of scientific schools [20, 21, 5, 22, 7].

E.A. Aripov et al. used a number of polymers and presented a fairly complete list of methods of the physicochemical method according to the criterion of the materials used, classifying them according to the structure of molecules and molecular weight [20]. However, in the sections devoted to the impregnation of a sandy substrate with chemical ameliorants, there are no clear patterns of the effect of molecular weight on the impregnation process and the formation of the structure of the layer of fixed sand. Undoubtedly, the classification according to the type of bonds formed between the sand particles is important. The generalizing classification is based on the origin of the chemical ameliorant.

In the work of T.I. Fazilov [5], who made a significant contribution to the development of methods (6 A.S.), substantiated the physical and mechanical characteristics and parameters of protective layers resistant to the impact of wind-sand flow.

In the works of M.M. Mirakhmedov substantiates measures based on the principle of resource conservation, which should be further developed along the way of expanding water-soluble binders from waste and secondary products of local production with preliminary moistening of the fixed sand surface [27].

Also promising is the cultivation of biomass on sands, for example, from cyanobacteria and some species of mosses, which, being biological and environmentally friendly, are the most promising measures $[25,26]$, blocking the source of deflation like a protective crust.

\section{Conclusions}

1. With the similarity of the measures used to reduce the negative impact of sand drifts and blowing of the roadbed of railways in the conditions of sandy deserts in China, Central Asia, Africa and Brazil, cellular protection is preferably used. Despite the abundance of experiments in the aerodynamic channel, substantiation of the cell size awaits further theoretical generalizations and extensive experimental studies, in particular, the cell size in plan and in height has not been optimized. The issue of orientation of the sides of the cells relative to the 
railway route has not been studied in order to maximize their potential for retaining the transferred sand (sand storage potential of protection).

2. The use of fences and blown snow shields as measures to protect infrastructure from sand drifts is justified only by their use in combination with other measures in the context of creating a forest belt.

3. A promising measure for eliminating sources of deflation is the cultivation of cyanobacteria biomass on sand, which form a protective layer, as an example of an astringent-sand protective crust. Unlike PCM, which is used to improve the efficiency of the biological method, biomass production is itself a biological, environmentally friendly measure to combat sand drifts.

4. Substantial and semantic Russian-English identification of a number of keywords and phrases used in the protection of natural and technical infrastructures in sandy deserts has been completed.

\section{References}

"Windsand Stream", Geological Explanatory Dictionary.http://www.edudic.ru/geo/l/17/p/22/

L Raffaele, L Bruno.WindblownSandMitigationAlongRailwayMegaprojects: AComparativeStudy. Structural Engineering International, 1-10, 2020

Zakirov R.S. Railways in sandy deserts. -M: Transport, 1980.221 p.

Mirakhmedov M. Complex system of preparation for production of sand-fixing works and its effectiveness / Problems of mechanics, No. 2, 2002.

Fazilov T.I. Organomineral anti-deflation coatings obtained by impregnating mobile sands. Dissertation for the degree of Doctor of Technical Sciences - Kharkov, KhISI, 1991.-350 p.

Khodzhaev A.A. Controlling sand drifts on the railways. -M .: Transzheldorizdat, 1947. -104 p.

Mirakhmedov M.M. and other Resource-saving organizational and technological solutions to combat the manifestations of exogenous processes on the railways. - Tashkent: Sano, $2017.424 \mathrm{p}$.

Bruno L., Horvat M., Raffaele L. Windblown sand along railway infrastructures: a review of challenges and mitigation measures/ Journal of Wind Engineering and Industrial Aerodynamics. Vol. 177, 2018.

A.S. Stipho. Aeolian sand hazards and engineering design for desert regions/ Q. J. Eng. Geol., No $25,1992$.

Anurag, S. Problems in maintenance of indian railway in deserts and possible solutions/ UIC Workshop on Desert Railways.

Dong, G., Chen, X., He, Z., Han, X. Wang. Controlling blown sand along the highway crossing the Taklimakan Desert/ J. Arid Environ., No 57, 2004.

J.A. Zakeri, R. Abbasi. Field investigation of variation of loading pattern of concrete sleeper due to ballast sandy contamination in sandy desert areas/ J. Mech. Sci. Technol., No 26, 2012.

Lianchan, F., Jiqing, L., Yaoquan, D. Review on the prevention of sand damages to railway line in desert areas of China// J. Desert Res. 3. In (Chinese) // J. China Railw. Soc., 3 (1994)

M. Saifi, N. Boulghobra, L. Fattoum. The green Dam in Algeria as a Tool to Combat Desertification. Davos: Global Risk Forum, Vol. 3, 2015.

Merino, P. Arabia saudi: un reto exigente para la internacionalizacion de la tecnologia espanola. Lineas 80, 2014.

M. Rahim. Behaviour of Drift Sand and Method of Dealing with it, in: Pakistan Engineering Congress, 1945

Obruchev V.A. Selected works on the geography of Asia. T. 1. - M .: Geografgiz, 1951. - 502 p.

Paletskiy V.A. Selected works on afforestation and hydrogeology. -Tashkent: Publishing house of the Academy of Sciences of the Uzbek SSR, 1956.-144 p.

Polyakov V.P., Pesvianidze D.I., Gorbacheva V.F. Experience in dealing with sand drifts on the Central Asian railway. -Tashkent: UzINTI, 1966.-72 p.

Aripov E.A. B.N. Nuryev, M.A. Arazmuradov. Chemical reclamation of moving sands / Under. ed. K.S.Akhmedovand A.P. Ivanov. -Ashgabat: Ylym, 1983.

Recommendations for fixing mobile sands with binders / Comp. T.I. Fazilov, M. Mirakhmedov, A.I. Adylkhodzhaev et al. -M .: Transport, 1984. $32 \mathrm{p}$.

Mirakhmedov M. Fundamentals of methodology for organizing sand-fixing works and protection of natural and technical objects from sand drifts / Monograph. - Tashkent: Fan vatekhnolgyalar, 2008 . 248 p.

Ivlev N.P., Kamenev A.M. Experience of sand-fixing works on the roads of Kazakhstan / Control of sand drifts on the railway. Sat. scientific. tr. Issue 171/18. -Tashkent: TashIIT. -1981.

Mirzaakhmedov, Kh. S., Panekin VV. Trenches, shafts, shaft-ditches and ditches-shafts against sand drifts on the Central Asian road. Issues of design and construction of railways in the desert zone of Central Asia and Kazakhstan. Proceedings of TashIIT, vol. 160/8, 1980. p 60-69.

Ferran Garcia-Pichel, Martin F. Wojciechowski. The Evolution of a Capacity to Build Supra-Cellular Ropes Enabled Filamentous Cyanobacteria to Colonize Highly Erodible Substrates/ PLoS ONE. Vol. 4. Issue 11, 2009.

Zhou, X., Zhao, Y., Belnap, J., Zhang, B., Bu, C. and Zhang, Y. Practices of biological soil crust rehabilitation in China: experiences and challenges. Restor Ecol. doi:10.1111/rec.13148 
Mirakhmedov*, M.M., Muzaffarova, M.K. Prospectsfixationdriftsandsphysicochemicalmethod. Transport problems. Vol. 11. Issue 3. PP.143-152. 